\title{
Investigations on the synthesis and chemiluminescence of novel 2-coumaranones
}

\author{
Stefan Schramm, ${ }^{a}$ Dieter Weiß, ${ }^{\text {a }}$ Isabelle Navizet, ${ }^{\text {b,c }}$ Daniel Roca-Sanjuán, ${ }^{\text {d }}$ Herbert \\ Brandl, ${ }^{a}$ Rainer Beckert, ${ }^{a}$ and Helmar Görls ${ }^{a}$ \\ ${ }^{a}$ Friedrich-Schiller-Universität Jena, Institut für Organische Chemie und Makromolekulare \\ Chemie, Humboldtstraße 10, 07743 Jena, Germany \\ ${ }^{\mathrm{b}}$ Molecular Science Institute, School of Chemistry, Univesity of the Witwatersrand, PO Wits, \\ Johannesburg, 2050 South Africa \\ ${ }^{\mathrm{c}}$ Université Paris-Est, Laboratoire Modélisation et Simulation Multi Echelle, MSME UMR 8208 \\ CNRS, 5 bd Descartes, 77454 Marne-la-Vallée, France \\ ${ }^{\mathrm{d}}$ Department of Chemistry - Angström, Theoretical Chemistry Programme, Uppsala University, \\ 75002 Uppsala, Sweden \\ E-mail: c5diwe@rz.uni-jena.de
}

Dedicated to Prof. Dr. Steffen Albrecht 20.10.1957 - 19.07.2012

\begin{abstract}
Optimized syntheses of 2-coumaranone derivatives and, based thereon, several new representatives of this class of substances are described. They show a clearly visible chemiluminescence under the exposure of a strong base and in the presence of oxygen. The wavelength and intensity of the light emitted depends on both the substituents on the benzo annealed, as well as on the type of base used. A mechanism is presented in which a delocalized enolate is postulated as a key intermediate.
\end{abstract}

Keywords: Chemiluminescence, dioxetanone, 2-coumaranone, Tscherniac-Einhorn reaction

\section{Introduction}

Chemiluminescence is the emission of ultraviolet, visible or infrared light by the release of energy from a chemical reaction. The applications of chemiluminescence span children's toys, commercially available glow sticks, gas analysis (e.g. ozone-induced chemiluminescence) and the detection and assay of biomolecules ("ELISA," "Western blots") and enzymes ("AMPPD"). Even ultra-weak chemiluminescence is a frequently used method for trace analyses due to high- 
performance detectors. Generally, most chemiluminescence systems known today display only very weak or weak light emission. ${ }^{1-4}$ On the other hand, there is still a need for strongly emitting systems such as firefly luciferin and coelenterazine; both are important reagents for bioorganic analytics; however, their synthesis is very complex and expensive. Based on these facts, Lofthouse et al. ${ }^{5}$ developed a promising system in 1979 by using derivatives of 2-coumaranones (Scheme 1).

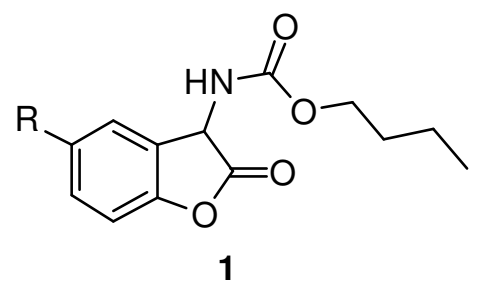
(a) $\mathrm{R}=\mathrm{Cl}$
(d) $\mathrm{R}=\mathrm{Me}$
(b) $\mathrm{R}=\mathrm{Br}$
(e) $\mathrm{R}=\mathrm{OMe}$
(c) $\mathrm{R}=\left[\mathrm{CH}_{2}\right]_{8} \mathrm{Me}$

Scheme 1. 2-Coumaranone's derivatives of Lofthouse et al.

Upon treatment in polar and aprotic solvents, the solutions of 1a showed a clearly visible blue chemiluminescence (Figure 1, 1a) on contact with air. Luminol, as a known chemiluminophore, is under the same conditions strongly exceeded by this system in both intensity and duration. The authors focused their activities on the exploration of the synthesis and the elucidation of the mechanism of the chemiluminescent reaction.

Figure 1. Chemiluminescence of (1a).

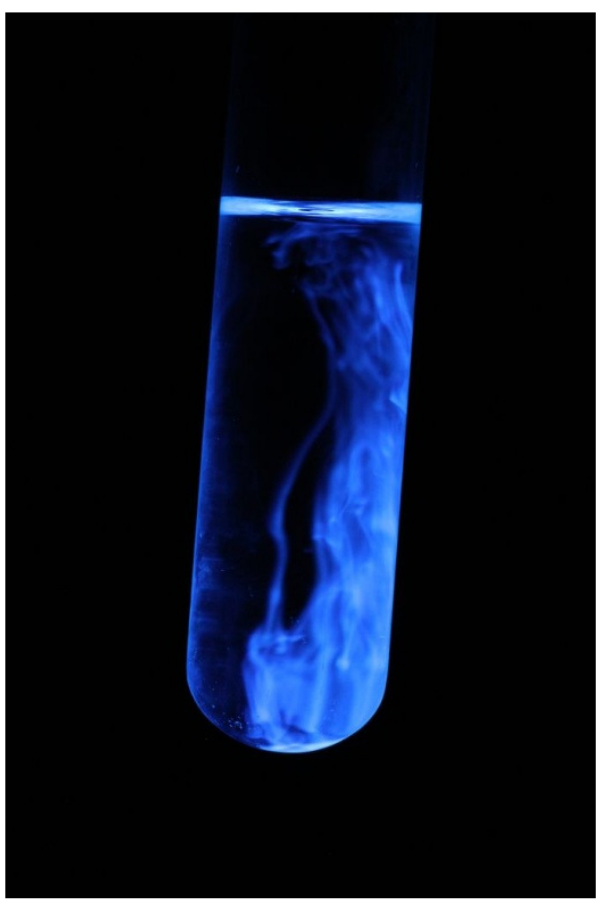


The 2-coumaranone's derivatives, despite their superior features, were lost in obscurity for a long time, and they only aroused renewed interest almost two decades after their discovery. ${ }^{6-9} \mathrm{In}$ addition to principal improvements of the synthesis, B. Matuszczak reported several new benzofused derivatives (Scheme 2).

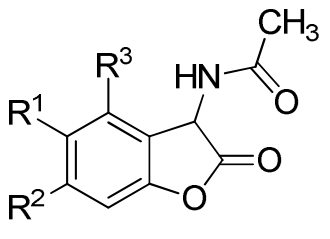

2<smiles>CC(=O)NC1C(=O)Oc2ccc3ccccc3c21</smiles>

3

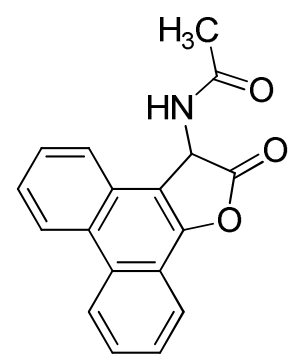

4
(a) $\mathrm{R}^{1}=\mathrm{Me}, \mathrm{R}^{2}=\mathrm{H}, \mathrm{R}^{3}=\mathrm{H}$
(e) $\mathrm{R}^{1}=\mathrm{OMe}, \mathrm{R}^{2}=\mathrm{H}, \mathrm{R}^{3}=\mathrm{H}$
(b) $\mathrm{R}^{1}=\mathrm{H}, \mathrm{R}^{2}=\mathrm{OH}, \mathrm{R}^{3}=\mathrm{H}$
(f) $R^{1}=\mathrm{OMe}, \mathrm{R}^{2}=\mathrm{OMe}, \mathrm{R}^{3}=\mathrm{OMe}$
(c) $\mathrm{R}^{1}=\mathrm{H}, \mathrm{R}^{2}=\mathrm{OMe}, \mathrm{R}^{3}=\mathrm{H}$
(g) $\mathrm{R}^{1}=\mathrm{Cl}, \mathrm{R}^{2}=\mathrm{H}, \mathrm{R}^{3}=\mathrm{H}$
(d) $\mathrm{R}^{1}=\mathrm{OH}, \mathrm{R}^{2}=\mathrm{H}, \mathrm{R}^{3}=\mathrm{H}$
(h) $\mathrm{R}^{1}=\mathrm{NO}_{2}, \mathrm{R}^{2}=\mathrm{H}, \mathrm{R}^{3}=\mathrm{H}$

Scheme 2. 2-Coumaranone derivatives synthesized by Matuszczak.

Particularly noteworthy is the attempt to integrate this type of compounds into an analytical application in the form of a peroxidase assay. Based on these earlier works, we are now presenting several new derivatives of the family of 2-coumaranones which show some unusual spectral features.

\section{Results and Discussion}

Both Matuszczak and Lofthouse et al. realized the synthesis of the target substances in the same way. We have optimized the process in detail but we used in principle the same method (Scheme $3)$. 
<smiles>[R]C(=O)NC(O)C(=O)O</smiles><smiles>[R]c1ccc(O)cc1</smiles><smiles>[R]C(=O)NC1C(=O)Oc2ccc([R])cc21</smiles>

5<smiles>[R]C(=O)NC(C(=O)O)c1cc([R])ccc1O</smiles>

9

(a) $\mathrm{R}^{1}=\mathrm{Br}, \mathrm{R}^{2}=$ Phenyl

(b) $\mathrm{R}^{1}=\mathrm{Cl}, \mathrm{R}^{2}=$ Phenyl

(c) $R^{1}=F, R^{2}=$ Phenyl

(d) $\mathrm{R}^{1}=\mathrm{Br}, \mathrm{R}^{2}=\mathrm{p}-$ Me-Phenyl

(e) $\mathrm{R}^{1}=\mathrm{Br}, \mathrm{R}^{2}=\mathrm{p}-\mathrm{Br}$-Phenyl

( f) $\mathrm{R}^{1}=\mathrm{Br}, \mathrm{R}^{2}=\mathrm{p}-\mathrm{NO}_{2}$-Phenyl

(g) $\mathrm{R}^{1}=\mathrm{Br}, \mathrm{R}^{2}=\left(\mathrm{CH}_{2}\right)_{12} \mathrm{CH}_{3}$

(h) $R^{1}=F, R^{2}=$ O-Butyl

Scheme 3. Synthesis of the new compounds.

Starting with glyoxylic acid (7) and an amide or a urethane (6), we first isolated the corresponding secondary amide (8). This was then transformed in the presence of a phenol by a Tscherniac-Einhorn reaction, ${ }^{10,11}$ and catalyzed by concentrated sulfuric acid to give the corresponding $\alpha$-amidoalkylation products (9). In addition to this "two-step" synthesis also a "one-pot" version is possible. Details are given in the experimental section. In the last step, water was eliminated by treatment with acetic anhydride forming the desired lactone (5). All compounds with phenylic structures in their side chain can be regarded as being derivatives of $\alpha$ hydroxyhippuric acid. This commercially available building-block can alternatively be prepared according to the literature. ${ }^{12-15}$ The synthesis of $(\mathbf{5 g})$ was accomplished starting from myristic acid amide, which is synthetically easily accessible from myristic acid. The spectral properties of all compounds are within the expected range and are given in detail in the experimental section. Single crystal X-ray analysis obtained from suitable single crystals of derivative (5a) allowed an unambiguous structural assignment of this compound, as shown in Figure 4. The bond lengths and angles are in the expected range. 
If the compounds (5) are treated with a strong base, such as 1,8-diazabicyclo [5.4.0] undec-7ene (DBU), in polar aprotic solvents, such as THF, DMF, acetone, or dibutyl phthalate, a strong chemiluminescence can immediately be observed. The color of the emitted light varies depending on the type of the substituent $\mathrm{R}^{1}$ and $\mathrm{R}^{2}$ at the fused benzo-ring, ranging from blue $(\mathbf{5 g})$ to green (5a) to orange-red (5e) (Figure 2).

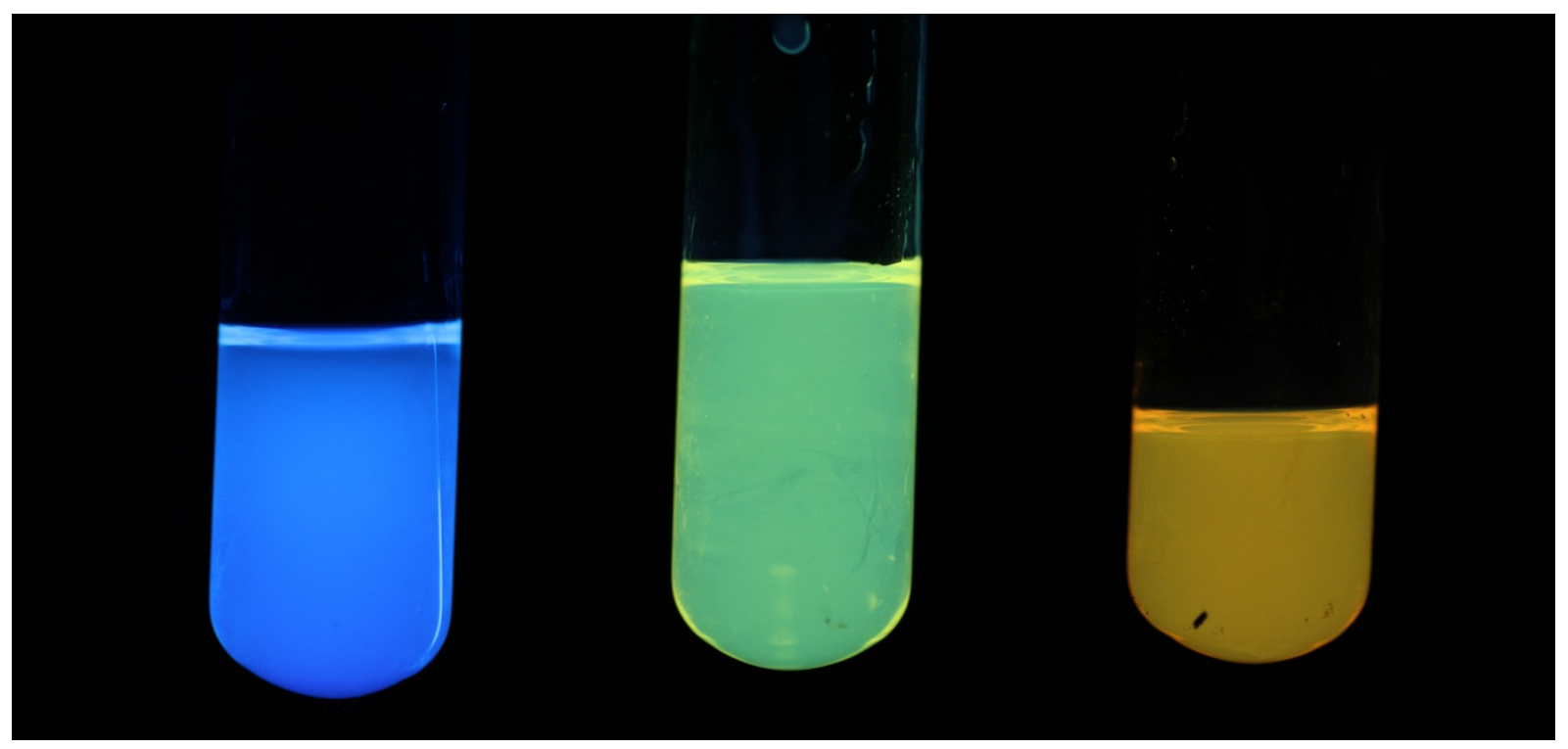

Figure 2. From left to right. chemiluminescence of (5g), (5a) and (5e).

The intense light emission can be observed over several minutes and can be reactivated by supplying new oxygen from air. It can be generally stated that the more electron-poor the aromatic center is, the more intensive is the emission of light. This is particularly achieved with the position of the fluorine substituent on the aromatic ring, so that the chemiluminescence of the compound (5h) is clearly visible even in daylight. On the other hand, the introduction of a nitro group, as in derivative (5f), resulted in the complete quenching of the chemiluminescence. The fact that the more electron-poor the aromatic center is, the more intensive is the emission of light, could be explained by the higher stability of the corresponding anion formed, making the hydrogen atom more acid. The fact that the nitro derivative does not lead to CL emission might be explained by the much higher stability of the anion, making it less reactive to oxygen. The chemiluminescence spectra of the new compounds (5a-c) and the fluorescence of the resulting spent solutions are depicted in Figure 3, whereas the data of all other compounds are summarized in Table 1. 

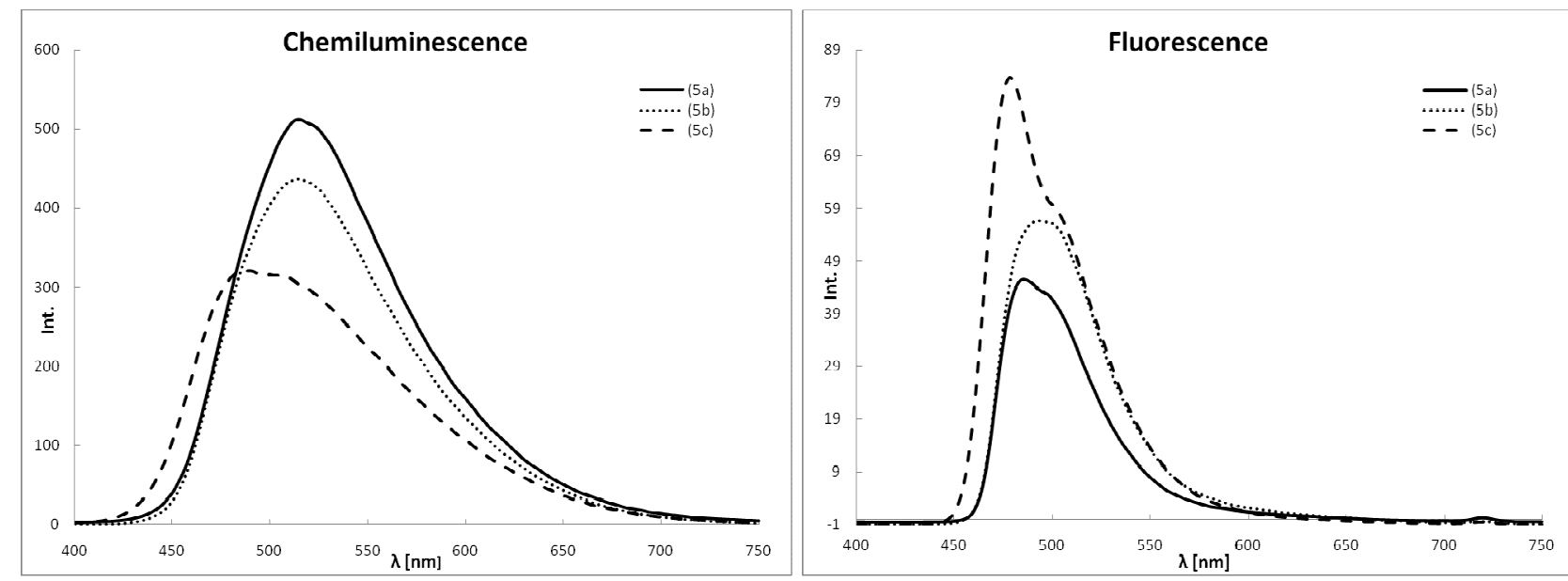

Figure 3. Chemiluminescence spectra of (5a-c) and Fluorescence spectra of the resulting spent solution of (5a-c).

Table 1. Chemiluminescence of synthesized compounds and Fluorescence of the resulting spent solution spectra maxima

\begin{tabular}{ccc}
\hline Compound & $\begin{array}{c}\text { Chemiluminescence, } \\
(\mathrm{nm})\end{array}$ & $\begin{array}{c}\text { Fluorescence, } \\
(\mathrm{nm})\end{array}$ \\
\hline $\mathbf{( 5 a )}$ & 514 & 486 \\
$\mathbf{( 5 b )}$ & 512 & 494 \\
$\mathbf{( 5 c )}$ & 490 & 480 \\
$\mathbf{( 5 d )}$ & 498 & 500 \\
$\mathbf{( 5 e )}$ & 562 & 559 \\
$\mathbf{( 5 g )}$ & 452 & 458 \\
$\mathbf{( 5 h )}$ & 448 & 450 \\
$\mathbf{( 1 0 )}$ & - & 482 \\
\hline
\end{tabular}

Surprisingly, the wavelength of the chemiluminescence of all derivatives measured differs substantially from the wavelength of the fluorescence of the resulting spent solution. This shift probably resulted from a change in molecular geometry after chemiluminescent light have been emitted. Such differences between the spectra have been observed only rarely, however, they have been explained by quantum chemical methods. ${ }^{16}$ Moreover, theoretical investigations are currently being performed and will be published separately.

Lofthouse et al. were able to postulate a suitable mechanism for the base-induced chemiluminescence of selected members of type (1) due to the isolation of stable oxidation products. Analogously, we succeeded in the isolation of the final oxidation product of the chemiluminescence reaction of (5a). For this purpose, equimolar ratios of (5a) and DBU were stirred in acetone under an oxygen atmosphere for several days. When the reaction was completed (TLC), the isolation was carried out by several consecutive chromatographical steps. 
Spectroscopic methods and the comparison with an authentic sample revealed the structure of $\mathrm{N}$ benzoyl-5-bromo-2-hydroxybenzamide (Scheme 4).

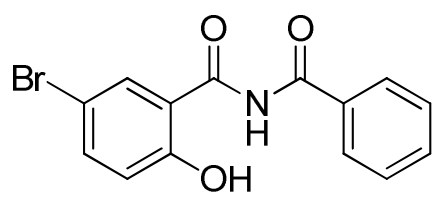

10

Scheme 4. Product of the chemiluminescence of (5a).

Finally, the fluorescence spectrum of derivative $\mathbf{1 0}$ was recorded. Its comparison with that of the resulting spent solution of $\mathbf{5 a}$ revealed only a small difference of $4 \mathrm{~nm}$ of the maximum. Thus, it can be assumed that compound (10) or its deprotonated form constitutes the main product of the chemiluminescence reaction of lactone (5a). Therefore, we suggest the following mechanism (Scheme 5) in analogy to Lofthouse et al.

The first step is undoubtedly the deprotonation of the lactone by the base DBU on the ring $\alpha$ carbon. The direct addition of (triplet) oxygen to the deprotonated substrate, yielding the peroxyanion (13), is spin-forbidden and cannot occur unless there is a spin inversion involved (inter-system crossing), which is facilitated via a spin-orbit coupling. A different pathway would leads the electron-rich enolate (11) thus formed, undergoes a single electron transfer (SET) in the presence of oxygen from air which forms a radical (12). Then, a further molecule of oxygen is attacked leading, via a peroxide radical, to the hydroperoxide anion (13). In the last step, this anion attacks the lactone carbonyl group intramolecularly under the formation of an 1,2dioxetanone ring system (14). It is well-known that such strained four-rings are able to split up carbon dioxide under the emission of light. ${ }^{18}$

Hitherto, only DBU was used as a base for initiating the chemiluminescence reaction observed in our experiments. This enabled a mostly suitable activation of the reaction. Other types of bases were examined in order to optimize the light emission. Therefore, the chemiluminescence of compound (5a) in THF solutions $\left(c=10^{-2} \mathrm{~mol} / \mathrm{l}\right)$ was measured. The details are given in the experimental section. All $\mathrm{pK}_{\mathrm{A}}$-values presented are given in relation to acetonitrile as solvent ${ }^{19}$ and the results are depicted in Table 2. 
<smiles>[R]C(=O)NC1C(=O)Oc2ccc(Br)cc21</smiles>

$5 a$<smiles></smiles>

13

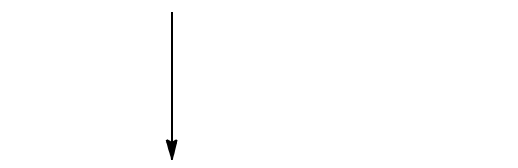<smiles>[R]C(=O)NC1(c2cc(Br)ccc2O)OOC1=O</smiles>

14<smiles></smiles>

11<smiles>[R]C(=O)N[C@H]1C(=O)Oc2ccc(Br)cc21</smiles><smiles>[R]C(=O)NC(=O)c1cc(Br)ccc1[O-]</smiles>

Scheme 5. Postulated mechanism of the chemiluminescence reaction of (5a).

Table 2. Chemiluminescence intensity with different bases

\begin{tabular}{lcc}
\hline \multicolumn{1}{c}{ Base } & $\mathrm{pK}_{\mathrm{a}}(\mathrm{MeCN})$ & Chemiluminescence \\
\hline Phosphazenbase, P2-Et & $+32,94$ & $90,2 \%$ \\
DBU & $+24,34$ & $58,0 \%$ \\
DBN & $+23,89$ & $40,4 \%$ \\
Tetramethylguanidine & $+23,30$ & $34,9 \%$ \\
Pyrrolidine & $+19,56$ & - \\
Triethylamine & $+18,82$ & - \\
DABCO & $+18,29$ & - \\
Pyridine & $+12,53$ & - \\
\hline
\end{tabular}


As expected, the intensity of the emission was strongly dependent on the strength of the base used. The maximum brightness was achieved by using the phosphazene base P2-Et with a $\mathrm{pK}_{\mathrm{A}^{-}}$ value of +32.94 . No more luminescence could be observed visually when pyrrolidine with a base strength of +19.56 was employed. Further qualitative tests showed that, in contrast to alkoxides $(\mathrm{NaOEt}, \mathrm{K} t \mathrm{OBu})$, only neutral bases are capable of initiating the chemiluminescence reaction of coumaranone derivatives (5).

\section{Conclusions}

In conclusion we reinvestigated an old, but barely noticed system of chemiluminescent substances and we succeeded in synthesizing further derivatives of similar structure. For this purpose, the synthesis using easily available building blocks was optimized. Furthermore, the chemiluminescence as well as the fluorescence spectra of the new derivatives were recorded. According to a recent work of some of the authors, ${ }^{16}$ the wavelength shift between the fluorescence and chemiluminescence spectra might be attributed to a change in the geometry of the emissive molecule during the reaction. Exact calculations are still pending and will be presented in further publications. Also, the possible mechanism of the reaction reported here will be examined in more detail. The influence of base strength on the emission intensity was qualitatively evaluated.

Due to their simple synthetic entry and their strong chemiluminescence, derivatives of type (5) not only form the base for show experiments but also may serve for the development of new substrates for biochemical/medicinal applications.

\section{Experimental Section}

General. All reagents, unless otherwise noted, were received by commercial providers (SigmaAldrich $^{\circledR}$, TCI $^{\circledR}$, Acros Organics ${ }^{\circledR}$ ) and were used in the offered quality. All for the reactions require solvents were used in synthesis quality. Solvents which are marked with "dry", have been dried prior to use by conventional methods and distilled under nitrogen.

The progress of the synthesis was monitored by thin layer chromatography (Merck ${ }^{\circledR}$, silica gel 60 F254). The detection of the substances on the plates was carried out with UV light of wavelengths $254 \mathrm{~nm}$ and $366 \mathrm{~nm}$.

The listing of the NMR signals can be explained as follows: chemical shift in ppm (multiplicity, integral, assignment). The multiplicity is indicated by the acronyms s (singlet), $d$ (doublet), dd (double dupplett), $\mathrm{t}$ (triplet), q (quartet) and m (multiplet).

The UV-VIS spectra were recorded on a Thermo UNICAM UV 500 and SHIMADZU UV-1601, chemiluminescence and fluorescence spectra on a JASCO FP-6500. The tempering of samples 
was carried out by a LAUDA RK8 CS. The precise measurement parameters are given in the analytical procedures.

All NMR spectra were recorded on a Bruker AC $250\left({ }^{1} \mathrm{H}: 250 \mathrm{MHz},{ }^{13} \mathrm{C}: 63 \mathrm{MHz}\right)$ and AC 400 $\left({ }^{1} \mathrm{H}: 400 \mathrm{MHz},{ }^{13} \mathrm{C}: 100 \mathrm{MHz}\right)$. As an internal standard a chemical shift of the residual protons of the deuterated solvent was used in each case. The mass spectra were recorded on the devices FISONS Trio-200, FINNIGAN MAT SSQ 710 and SHIMADZU Biotech Axima LNR.

In general, the synthesis of the targets molecules was performed in two different ways:

\section{Route 1. "3-step synthesis"}

(a) amid coupling

$0.1 \mathrm{~mol}$ amide and $0.11 \mathrm{~mol}$ of glyoxylic acid monohydrate are dissolved in $75 \mathrm{ml}$ of acetone in a $250 \mathrm{ml}$ two-necked flask. After attaching a reflux condenser with drying tube and a thermometer it is stirred for 5 hours under reflux. After 2 hours the reaction product begins to precipitate. After the completion of the reaction, the reaction mixture is cooled to room temperature. This leads to the further crystallization of the secondary amide. Finally, the product is filtered off through a G2 frit and dried under vacuum.

b) Tscherniac-Einhorn reaction

0.03 moles of the secondary amide together with $0.035 \mathrm{~mol}$ of the corresponding phenol component are dissolved in a $100 \mathrm{ml}$ round bottom flask with $50 \mathrm{ml}$ of an acetic acidconcentrated sulfuric acid (9:1) mixture, and stirred for at least 24 hours at room temperature. The exact reaction times can be found in the corresponding product description. The reaction mixture is transferred into $250 \mathrm{ml}$ of cold water. In this process the product of the TscherniacEinhorn reaction precipitates. This is filtered off and used immediately for the lactonization. If there is no precipitation the aqueous phase is extracted with chloroform. The resulting organic phase is dried over sodium sulfate and concentrated in vacuum. The product thus obtained is used directly for further reaction.

c) lactonization

The resulting product of the Tscherniac-Einhorn reaction is given into a two necked flask equipped with a reflux condenser, a drying tube and a thermometer. After that it is suspended in $10 \mathrm{ml}$ of acetic anhydride and stirred at reflux for 30 minutes. After completion of the reaction, the reaction mixture is cooled to room temperature and allowed to stand overnight in the refrigerator. If the product crystallized in the following it is filtered. If no crystals are forming, the reaction mixture is treated with $-20^{\circ} \mathrm{C}$ cold diethyl ether. After this the precipitate is filtered off and dried under vacuum.

\section{Route 2. „One pot synthesis”}

a) amid coupling und Tscherniac-Einhorn reaction 0.03 moles of the amide together with 0.03 mol glyoxylic acid monohydrate are dissolved in a $100 \mathrm{ml}$ round bottom flask with $50 \mathrm{ml}$ of an acetic acid-concentrated sulfuric acid (9:1) mixture. After 30 minutes of stirring at room temperature $0.035 \mathrm{~mol}$ of the corresponding phenol 
component are added. Now it is stirred for at least 24 hours at room temperature. The exact reaction times can be found in the corresponding product description. The reaction mixture is transferred into $250 \mathrm{ml}$ of cold water. This is filtered and used immediately for the lactonization. If there is no precipitation the aqueous phase is extracted with chloroform. The resulting organic phase is dried over sodium sulfate and concentrated in vacuum. The product thus obtained is used directly for further reaction.

b) lactonization

The lactonization at Route 2 is the same as at Route 1

$N$-(5-Bromo-2-oxo-2,3-dihydrobenzofuran-3-yl)benzamide (5a). According to route $1 \mathrm{~b}$ and $\mathrm{c}$ starting form alpha hydroxy hippuricacid and para-bromophenol, $24 \mathrm{~h}$ stirring, white powder, $\mathrm{mp}$ $235{ }^{\circ} \mathrm{C}$ (dec.), Yield: $20 \%$; ${ }^{1} \mathrm{H}-\mathrm{NMR}:\left(250 \mathrm{MHz}, \mathrm{THF}-d_{8}\right): \delta 8.8(\mathrm{~d}, 1 \mathrm{H}, \mathrm{NH}), 7.8(\mathrm{~m}, 2 \mathrm{H}$, Phenyl), 7.4 (m, 5H, Phenyl), 7.1 (d, 1H, Phenyl), 5.6 (d, 1H, CH); ${ }^{13} \mathrm{C}-\mathrm{NMR}$ : (62.5 MHz, THF$\left.d_{8}\right): \delta 169.9,164.3,151.6,131.3,130.3,129.7,127.1,126.3,125.4$,125.1, 114.1, 110.2, 49.1;

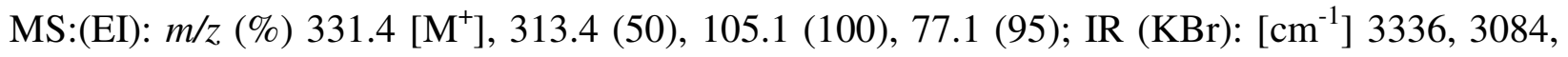
2937, 1827, 1640, 1520, 1469, 1323, 1126, 1075; Elemental analysis: $\mathrm{C}_{15} \mathrm{H}_{10} \mathrm{NO}_{3} \mathrm{Br}$ calculated: C, 54.24; H, 3.03; N, 4.22; Br, 24.06; found: C, $54.23 ; \mathrm{H}, 2.81 ; \mathrm{N}, 3.96 \mathrm{Br}, 23.90$ X-RAY:

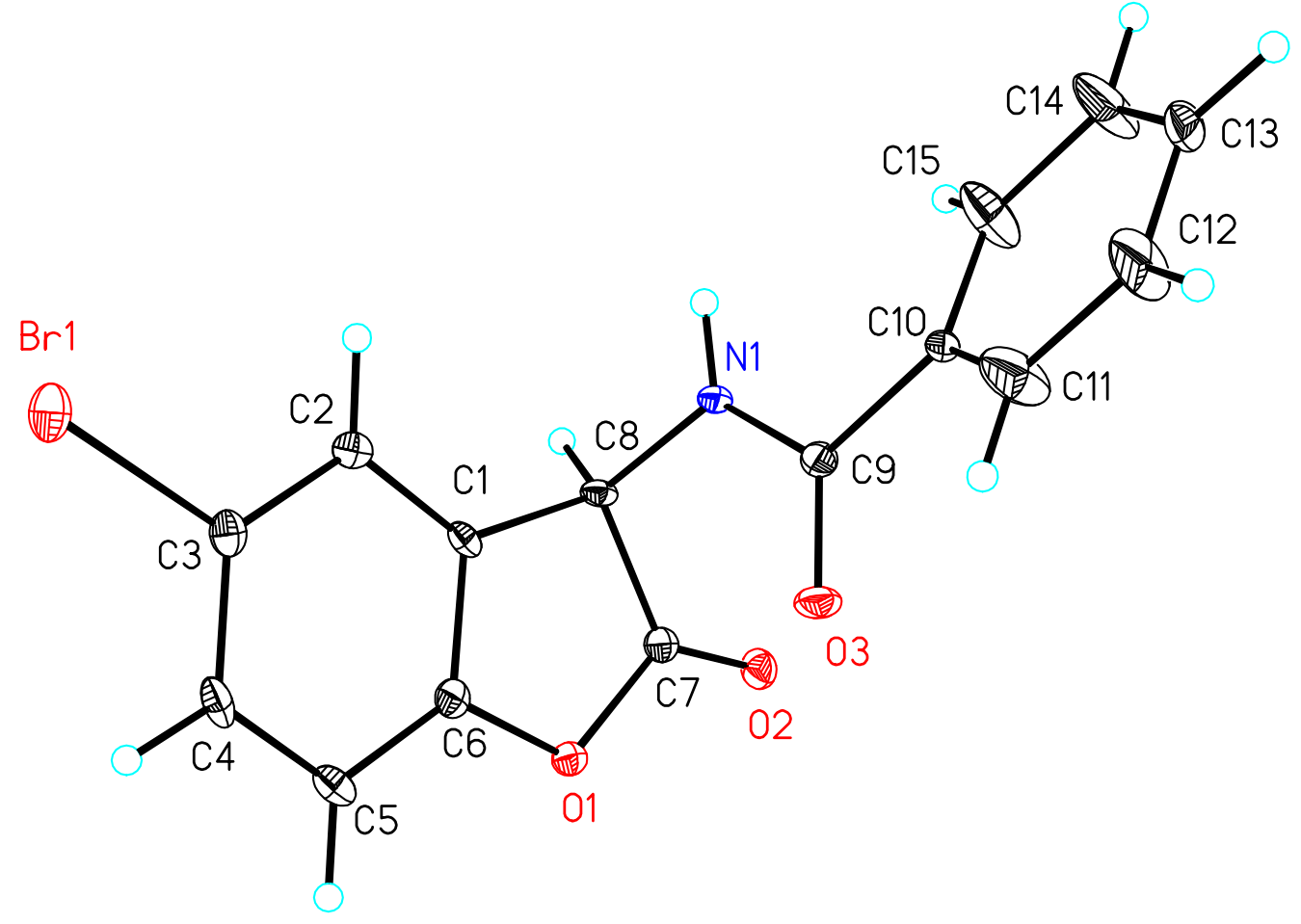

Figure 4. Molecular structure and numbering scheme of (5a). The ellipsoids represent a probability of $40 \%, \mathrm{H}$ atoms are drawn with arbitrary radii. 
$N$-(5-Chloro-2-oxo-2,3-dihydrobenzofuran-3-yl)benzamide (5b). According to route $1 \mathrm{~b}$ and c starting form alpha hydroxy hippuricacid and para-chlorophenol, 24h stirring, white powder, $\mathrm{mp}$ $240{ }^{\circ} \mathrm{C}$ (dec.), Yield: 28\%; ${ }^{1} \mathrm{H}-\mathrm{NMR}:\left(250 \mathrm{MHz}, \mathrm{THF}-d_{8}\right): \delta 8.7(\mathrm{~d}, 1 \mathrm{H}, \mathrm{NH}), 7.9(\mathrm{~m}, 2 \mathrm{H}$, Phenyl), 7.4 (m, 5H, Phenyl), 7.1 (d, 1H, Phenyl), 5.6 (d, 1H, CH); ${ }^{13} \mathrm{C}-\mathrm{NMR}:(62.5 \mathrm{MHz}$, THF$\left.d_{8}\right): \delta 170.1,164.3,151.1,131.3,129.7,127.3,126.9,126.6,126.3,125.4,122.3,109.7,49.2$; MS:(EI): $m / z(\%) 287.4\left[\mathrm{M}^{+}\right], 269.4$ (65), 105.2 (100), 77.1 (95); IR (KBr): [cm $\left.{ }^{-1}\right]$ 3332, 3081, 2936, 1826, 1639, 1519, 1466, 1323, 1076; Elemental analysis: $\mathrm{C}_{15} \mathrm{H}_{10} \mathrm{NO}_{3} \mathrm{Cl}$ calculated: $\mathrm{C}$, 62.62; H, 3.50; N, 4.87; Cl, 12.32; found: C, 62.36; H, 3.43; N, 4.68; Cl, 12.12.

$\boldsymbol{N}$-(5-Fluoro-2-oxo-2,3-dihydrobenzofuran-3-yl)benzamide (5c). According to route $1 \mathrm{~b}$ and c starting form alpha hydroxy hippuricacid and para-fluorophenol, 24h stirring, white powder, $\mathrm{mp}$ $249{ }^{\circ} \mathrm{C}$ (dec.), Yield: $8 \%$; ${ }^{1} \mathrm{H}-\mathrm{NMR}:\left(250 \mathrm{MHz}, \mathrm{THF}-d_{8}\right): \delta 8.8$ (s, $\left.1 \mathrm{H}, \mathrm{NH}\right), 7.8$ (m, 2H, Phenyl), 7.5 (m, 3H, Phenyl), 7.1 (m, 3H, Phenyl); ${ }^{13} \mathrm{C}-\mathrm{NMR}:\left(62.5 \mathrm{MHz}, \mathrm{THF}-d_{8}\right): \delta 171.9,166.1,157.5$, 149.9, 132.3, 131.7, 128.4, 127.4, 124.1, 118.1, 117.7, 112.0, 111.8, 110.3, 62.4; MS:(EI): $\mathrm{m} / z$ (\%) $271.5\left[\mathrm{M}^{+}\right], 253.4$ (80), 105.1 (100), 77.1 (95); IR (KBr): [cm $\left.{ }^{-1}\right]$ 3411, 3368, 3079, 1795, 1666, 1509, 1474, 1293, 1194, 1136, 1089, 794, 712; Elemental analysis: $\mathrm{C}_{15} \mathrm{H}_{10} \mathrm{NO}_{3} \mathrm{~F}$ calculated: C, 66,42; H, 3,72; N, 5,16; found : C, 66,68; H, 3,05; N, 4,98.

$N$-(5-Bromo-2-oxo-2,3-dihydrobenzofuran-3-yl)-4-methylbenzamide (5d). According to route $1 \mathrm{~b}$ and $\mathrm{c}$ starting form $\mathrm{p}$-methyl alpha hydroxy hippuricacid and para-bromophenol, $24 \mathrm{~h}$ stirring, white powder, mp $252{ }^{\circ} \mathrm{C}$ (dec.), Yield: 9\%; ${ }^{1} \mathrm{H}-\mathrm{NMR}:\left(250 \mathrm{MHz}, \mathrm{DMSO}-d_{6}\right): \delta 9.7$ (d, 1H, NH), 7.5 (m, 7H, Phenyl), 5.5 (d, 1H, CH), 2.3 (s, 3H, $\left.\mathrm{CH}_{3}\right) ;{ }^{13} \mathrm{C}-\mathrm{NMR}$ : (62.5 MHz, DMSO$\left.d_{6}\right): \delta 173.3,166.4,153.2,142.7,132.7,132.4,129.8,129.5,127.9,126.9,116.2,112.9$, 51.6, 21.5; MS:(EI): m/z (\%) $345\left[\mathrm{M}^{+}\right], 329$ (20), 119 (100), 91 (80), 65 (60); Elemental analysis: $\mathrm{C}_{16} \mathrm{H}_{12} \mathrm{NO}_{3} \mathrm{Br}$ calculated: $\mathrm{C}, 55.51 ; \mathrm{H}, 3.49 ; \mathrm{N}, 4.05 ; \mathrm{Br}, 23.08$; found: $\mathrm{C}, 55.38 ; \mathrm{H}, 3.62 ; \mathrm{N}, 4.20$ $\mathrm{Br}, 23.36$;

$N$-(5-Bromo-2-oxo-2,3-dihydrobenzofuran-3-yl)-4-brombenzamide (5e). According to route $1 \mathrm{~b}$ and $\mathrm{c}$ starting form $\mathrm{p}$-bromo alpha hydroxy hippuricacid and para-bromophenol, $24 \mathrm{~h}$ stirring, pale yellow powder, mp $256{ }^{\circ} \mathrm{C}$ (dec.), Yield: 7\%; ${ }^{1} \mathrm{H}-\mathrm{NMR}:\left(250 \mathrm{MHz}, \mathrm{DMSO}-d_{6}\right): \delta 9.9$ (d, $1 \mathrm{H}, \mathrm{NH}), 7.5$ (m, 7H, Phenyl), $5.6(\mathrm{~d}, 1 \mathrm{H}, \mathrm{CH}) ;{ }^{13} \mathrm{C}-\mathrm{NMR}:\left(62.5 \mathrm{MHz}, \mathrm{DMSO}-d_{6}\right): \delta 173.1$, 165.7, 153.2, 132.5, 132.4, 131.8, 130.0, 129.2, 127.1, 126.5, 116.2, 113.0, 51.7; MS:(EI): $\mathrm{m} / z$ (\%) $411\left[\mathrm{M}^{+}\right], 393$ (20), 183 (100), 155 (36), 76 (20); Elemental analysis: $\mathrm{C}_{15} \mathrm{H}_{9} \mathrm{NO}_{3} \mathrm{Br}_{2}$ calculated: C, 43.83; H, 2.21; N, 3.41; Br, 38.88; found: C, 43.98; H, 2.03; N, 3.25; Br, 38.51.

$\mathrm{N}$-(5-Bromo-2-oxo-2,3-dihydrobenzofuran-3-yl)-4-nitrobenzamide (5f). According to route 2 starting form para-nitrobenzamide, glyoxylic acid monohydrate and para-bromophenol, $24 \mathrm{~h}$ stirring, white powder, mp $186{ }^{\circ} \mathrm{C}$ (dec.), Yield: 6\%; ${ }^{1} \mathrm{H}-\mathrm{NMR}:\left(250 \mathrm{MHz}, \mathrm{DMSO}-d_{6}\right): \delta 10.1$ (d, $1 \mathrm{H}, \mathrm{NH}), 7.0\left(\mathrm{~m}, 7 \mathrm{H}\right.$, Phenyl), 5.6 (d, 1H, CH); ${ }^{13} \mathrm{C}-\mathrm{NMR}:\left(62.5 \mathrm{MHz}\right.$, DMSO- $\left.d_{6}\right): \delta 172.9$, 166.7, 153.2, 149.5, 140.4, 138.2, 132.6, 129.5, 127.2, 123.8, 116.5, 113.0, 51.7; MS:(EI): $\mathrm{m} / z$ (\%) $376\left[\mathrm{M}^{+}\right], 358$ (30), 166 (92), 150 (100), 104 (80), 76 (75); Elemental analysis: $\mathrm{C}_{15} \mathrm{H}_{9} \mathrm{~N}_{2} \mathrm{O}_{5} \mathrm{Br}$ calculated: $\mathrm{C}, 47.77 ; \mathrm{H}, 2.41 ; \mathrm{N}, 7.43 ; \mathrm{Br}, 21.19$; found: $\mathrm{C}, 47.97 ; \mathrm{H}, 2.38 ; \mathrm{N}$, 7.66; $\mathrm{Br}, 20.87$. 
$N$-(5-Bromo-2-oxo-2,3-dihydrobenzofuran-3-yl)tetradecanamide (5g). According to route 2 starting form myristic acid amide, glyoxylic acid monohydrate and para-bromophenol, $48 \mathrm{~h}$ stirring, white powder, mp $124{ }^{\circ} \mathrm{C}$ (dec.), Yield: 7\%; ${ }^{1} \mathrm{H}-\mathrm{NMR}:\left(250 \mathrm{MHz}, \mathrm{DMSO}-d_{6}\right): \delta 9.0(\mathrm{~d}$, 1H, NH), 7.3 (m, 3H ,Phenyl), 5.3 (d, 1H, CH), 2.1 (t, 2H, $\left.\mathrm{CH}_{2}\right), 1.4\left(\mathrm{~m}, 2 \mathrm{H}, \mathrm{CH}_{2}\right), 1.2(\mathrm{~m}, 20 \mathrm{H}$, $\mathrm{CH}_{2}$ ), 0.8 (t, 3H, $\mathrm{CH}_{3}$ ); ${ }^{13} \mathrm{C}-\mathrm{NMR}:\left(62.5 \mathrm{MHz}, \mathrm{DMSO}-d_{6}\right): \delta 173.2,153.1,132.3,129.6,126.8$, 116.0, 112.9, 51.1, 34.7, 31.7, 29.47, 29.45, 29.40, 29.1, 28.7, 25.4, 22.5, 14.4; MS:(EI): $m / z(\%)$ $437\left[\mathrm{M}^{+}\right], 211$ (28), 199 (100), 57 (48), 43 (72); Elemental analysis: $\mathrm{C}_{22} \mathrm{H}_{32} \mathrm{NO}_{3} \mathrm{Br}$ calculated: C, 60.27; H, 7.36; N, 3.19; Br, 18.23; found: C, 60.44; H, 7.46; N, 3.02; Br, 18.01.

Butyl 5-fluoro-2-oxo-2,3-dihydrobenzofuran-3-ylcarbamat $(5 \mathrm{~h})$. According to route 2 starting form n-butylcarbamate, glyoxylic acid monohydrate and para-fluorophenol, $48 \mathrm{~h}$ stirring, white powder, mp $136{ }^{\circ} \mathrm{C}$ (dec.), Yield: $43 \%$, no lactonization needed; ${ }^{1} \mathrm{H}-\mathrm{NMR}$ : $(250 \mathrm{MHz}$, DMSO$\left.d_{6}\right): \delta 8.4(\mathrm{~d}, 1 \mathrm{H}, \mathrm{NH}), 7.3\left(\mathrm{~m}, 3 \mathrm{H}\right.$,Phenyl), $5.2(\mathrm{~d}, 1 \mathrm{H}, \mathrm{CH}), 3.9\left(\mathrm{t}, 2 \mathrm{H}, \mathrm{CH}_{2}\right), 1.5\left(\mathrm{~m}, 2 \mathrm{H}, \mathrm{CH}_{2}\right)$, $1.2\left(\mathrm{~m}, 2 \mathrm{H}, \mathrm{CH}_{2}\right), 0.9\left(\mathrm{t}, 3 \mathrm{H}, \mathrm{CH}_{3}\right) ;{ }^{13} \mathrm{C}-\mathrm{NMR}$ : (62.5 MHz, DMSO-d $\left.d_{6}\right): \delta 173.6,153.9,130.3$, 129.1, 128.1, 122.4, 116.9, 112.4, 62.8, 53.1, 31.1, 18.7, 14.5; MS:(ESI): $m / z$ (\%) $267\left[\mathrm{M}^{+}\right]$; Elemental analysis: $\mathrm{C}_{13} \mathrm{H}_{14} \mathrm{NO}_{4} \mathrm{~F}$ calculated: $\mathrm{C}, 58.42 ; \mathrm{H}, 5.28 ; \mathrm{N}, 5.24$; found: $\mathrm{C}, 58.16 ; \mathrm{H}, 5.10$; N, 5.41 .

\section{Analytical methods}

Qualitative (visual) observation. For pure visual observation of the chemiluminescence about $10 \mathrm{mg}$ of the analyte were dissolved in about $2 \mathrm{ml}$ of dibutyl phthalate, or DMF and $20 \mu \mathrm{l}$ of DBU were added. The chemiluminescence is instantly visible for several minutes in a dimmed room and can be renewed by shaking the reaction vessel.

Chemiluminescence and fluorescence spectra. All measurements were performed in a $10^{-2}$ molar THF solution of the analyte. Unless otherwise indicated, they were carried out at $20{ }^{\circ} \mathrm{C}$. In detail, there are $20 \mu \mathrm{l} \mathrm{DBU}$ pipetted into the $2 \mathrm{ml}$ tempered analysis solution submitted in the cuvette. After this the chemiluminescence spectra were recorded. After the decay of the chemiluminescence (typically after $30 \mathrm{~min}$ ), the fluorescence was measured at an excitation wavelength of $360 \mathrm{~nm}$. All Chemiluminescence intensities using different bases were expressed relative with respect to the absolute white out of a grayscale picture of a solution of the analyte after the addition of different bases under room conditions.

Crystal Structure Determination. The intensity data for the compounds were collected on a Nonius KappaCCD diffractometer using graphite-monochromated $\mathrm{Mo}-\mathrm{K}_{\alpha}$ radiation. Data were corrected for Lorentz and polarization effects but not for absorption effects. ${ }^{20,21}$

The structures were solved by direct methods (SHELXS ${ }^{22}$ ) and refined by full-matrix least squares techniques against $\mathrm{Fo}^{2}$ (SHELXL-97 ${ }^{22}$ ). The hydrogen atom of the amine-group N1 was located by difference Fourier synthesis and refined isotropically. All other hydrogen atoms were included at calculated positions with fixed thermal parameters. All non-hydrogen atoms were refined anisotropically. ${ }^{22}$ XP (SIEMENS Analytical X-ray Instruments, Inc.) was used for structure representations. 
Crystal Data for (5a). $\mathrm{C}_{15} \mathrm{H}_{10} \mathrm{BrNO}_{3}, \mathrm{Mr}=332.15 \mathrm{gmol}^{-1}$, colourless prism, size $0.06 \times 0.02 \mathrm{x}$ $0.02 \mathrm{~mm}^{3}$, monoclinic, space group P 21/c, a = 9.0165(4), b = 5.0121(2), $\mathrm{c}=28.1800(9) \AA, \beta=$ 95.402(2) $)^{\circ}, \mathrm{V}=1267.84(9) \AA^{3}, \mathrm{~T}=-140{ }^{\circ} \mathrm{C}, \mathrm{Z}=4, \rho_{\text {calcd. }}=1.740 \mathrm{gcm}^{-3}, \mu\left(\mathrm{Mo}-\mathrm{K}_{\alpha}\right)=32.48 \mathrm{~cm}^{-}$ ${ }^{1}, \mathrm{~F}(000)=664,6851$ reflections in $\mathrm{h}(-11 / 9), \mathrm{k}(-6 / 6), 1(-36 / 36)$, measured in the range $2.81^{\circ} \leq \Theta$ $\leq 27.49^{\circ}$, completeness $\Theta \max =98.5 \%, 2881$ independent reflections, $\mathrm{R}_{\mathrm{int}}=0.0695,2005$ reflections with $\mathrm{F}_{\mathrm{o}}>4 \sigma\left(\mathrm{F}_{\mathrm{o}}\right), 185$ parameters, 0 restraints, $\mathrm{R} 1_{\mathrm{obs}}=0.0765, \mathrm{wR}^{2}{ }_{\text {obs }}=0.1190, \mathrm{R} 1_{\text {all }}$ $=0.1193, \mathrm{wR}^{2}$ all $=0.1331, \mathrm{GOOF}=1.233$, largest difference peak and hole: $0.520 /-0.494 \mathrm{e} \AA^{-3}$. Supporting Information available. Crystallographic data (excluding structure factors) has been deposited with the Cambridge Crystallographic Data Centre as supplementary publication CCDC-880411 for (5a). Copies of the data can be obtained free of charge on application to CCDC, 12 Union Road, Cambridge CB2 1EZ, UK [E- mail: deposit@ccdc.cam.ac.uk].

\section{Acknowledgments}

I.N. thanks the financial assistance of the South African National Research Foundation (NRF) and the university of the Witwatersrand (SPARC). D.R.-S. acknowledges the Swedish Research Council and the projects CTQ2010-14892 and CSD2007-0010 Consolider Ingenio in Molecular Nanoscience of the Spanish MICINN/FEDER and the Generalitat Valenciana.

\section{References}

1 Su, Y.; Chen, H.; Wang, Z.; Lu, Y. Appl. Spectr. Rev. 2007, 42, 139-176. http://dx.doi.org/10.1080/05704920601184275

2 Hu, L.; Xu,; G. Chem. Soc. Rev. 2010, 39, 3275-3304. http://dx.doi.org/10.1039/b923679c; PMid:20593100

3 Vasil'ev, R. F.; Tsaplev, Y. B. Russ. Chem. Rev. 2006, 75, 989. http://dx.doi.org/10.1070/RC2006v075n11ABEH003631

4 Bowie, R.; Sanders, M. G.; Worsfold, P. J. J. Biolumin. Chemilumin. 1996, 11,61-90. http://dx.doi.org/10.1002/(SICI)1099-1271(199603)11:2<61::AID-BIO406>3.0.CO;2-O

5 Lofthouse, G. J.;Suschitzky, H.; Wakefield, B. J.;Whittaker, R. A.; Tuck. B. J. Chem. Soc., Perkin Trans. 1 1979, 1634-1639. http://dx.doi.org/10.1039/p19790001634

6 Matuszczak.,B. Monatshefte für Chemie 1996, 127, 1291-1303. http://dx.doi.org/10.1007/BF00807797

7 Matuszczak, B. Pharmazie 1996, 51, 862-865

8 Matuszczak, B. Monatshefte für Chemie 1997, 128, 945-951. http://dx.doi.org/10.1007/BF00807104

9 Matuszczak, B. J. Prakt. Chem. 1998, 340, 20-25. http://dx.doi.org/10.1002/prac.19983400104 
10 Einhorn, A.; Bischkopff, E.; Szelinski, B. ;Schupp, G.; Spröngerts, E. ;Ladisch, C.; Mauermayer. T. Liebigs Ann. Chem. 1905, 343, 207-305. http://dx.doi.org/10.1002/jlac.19053430207

11 Matthies, D. Synthesis 1978, 53-54. http://dx.doi.org/10.1055/s-1978-24673

12 Zoller, U.; Ben-Ishai. D. Tetrahedron 1975, 31, 863-866. http://dx.doi.org/10.1016/0040-4020(75)80092-5

13 Ben-Ishai, D.; Satati, I.; Berler. Z. J. Chem. Soc., Chem. Commun. 1975, 24, 349-350. http://dx.doi.org/10.1039/c39750000349

14 Altman. J.; Moshberg, R.; Ben-Ishai. D. Tetrahedron Lett. 1975, 43, 3737-3740. http://dx.doi.org/10.1016/S0040-4039(00)91323-6

15 Ben-Ishai, D.; Satati, I.; Bernstein. Z. Tetrahedron 1976, 32, 1571. http://dx.doi.org/10.1016/0040-4020(76)85215-5

16 Roca-Sanjuán, D.; Delcey, M. G.; Navizet, I.; Ferré, N.; Liu, Y.; Lindh. R. J. Chem. Theory and Comput. 2011, 7, 4060-4069. http://dx.doi.org/10.1021/ct2004758

17 Hughes, E.C.; Titherley. A.W. J. Chem. Soc. 1911, 99, 23-29. http://dx.doi.org/10.1039/ct9119900023

18 Schmidt, S. P.; Schuster, G. B. J. Am. Chem. Soc. 1978, 100, 1966-1968. http://dx.doi.org/10.1021/ja00474a074

19 Kaljurand, I. J. Org. Chem. 2005, 70, 1019-1028. http://dx.doi.org/10.1021/jo048252w; PMid:15675863.

20 COLLECT, Data Collection Software; Nonius B.V., Netherlands, 1998.

21 Processing of X-Ray Diffraction Data Collected in Oscillation Mode; Z. Otwinowski, W. Minor, C. W. In Carter, R. M. Sweet, Eds.; Methods in Enzymology, Vol. 276, Macromolecular Crystallography, Part A, Academic: San Diego, 1997; p 307-326.

22 Sheldrick, G. M. Acta Cryst. 2008, 70, 112-122.

23 Spek, A. L. (1998) PLATON, A Multipurpose Crystallographic Tool, Utrecht University, Utrecht, The Netherlands. 